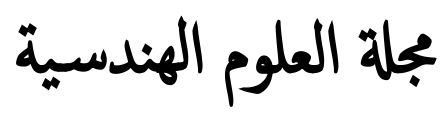

\title{
Beneficiation of Low-Grade and High-Phosphorus Iron Ore of Bajrawia, Sudan by Reverse Anionic Flotation: Potential of Microwave Treatment
}

\author{
A. ABBAKER ${ }^{1, *}$, E.M. MOSLIM ${ }^{1}$ and M.S. EL-SALMAWY ${ }^{2}$ \\ 1 Mining Engineering Department, Omdurman Islamic University, Omdurman, Sudan \\ 2 Faculty of Petroleum and Mining Engineering, Suez Canal University, Egypt \\ * Corresponding author: A. ABBAKER (e-mail: a7medelmubarak@yahoo.com ).
}

Article history: Received 15 April 2019, Received in revised form 04 May 2019, Accepted 16 May 2019

\begin{abstract}
Deposits of low grade and high-phosphorus iron ores are spreading globally, while the usage of this kind of deposits in the manufacturing of steel bounded which affect the quality of the produced steel. The Bajrawia deposit is one of the largest iron ore in Sudan but it only contains (35.5\% $\mathrm{Fe})$ and undesirable amount of phosphorus $(0.37 \% \mathrm{P})$. This paper investigated the utilization of reverse anionic flotation (RAF) for upgrading of iron and dephosphorization. Additionally, the effect of microwave pre-treatment on forth flotation performance on a laboratory scale. Microwave pre-treatment was applied on optimized reverse anionic flotation parameters in an account of iron grade $(47.31 \% \mathrm{Fe})$, iron recovery $(86.43 \%)$ and phosphorus content $(0.167 \% \mathrm{P})$. The findings into the microwave pre-treatment are quite promising. This investigation revealed that microwave heating improved the flotation response of iron grade to (51.94\%) and phosphorus content decreased into $(0.127 \% \mathrm{P})$ due to increase the liberation.
\end{abstract}

Keywords: High phosphorus iron ore, Liberation, Reverse anionic flotation, Microwave heating.

\section{INTRODUCTION}

Iron ore is the primary raw material from which metallic iron is extracted to make steel, but the iron content in the ore should be high enough to the production of steel and the inclusion of small amount of some elements such as alumina, phosphorus and sulphur can have profound effects on the behavioural characteristics of the product. The Bajrawia iron ore type is bog which occurs as goethite deposits formed in freshwater lakes under restricted conditions, presumably through bacterial or biochemical action. They generally characterized by high phosphorus content [1]. Phosphorus is a very destructive element has been found in iron ore used as material in steel production. It increases hardness and brittleness while decreases ductility on steel [2]. Phosphorus occurs in the form of phosphate adsorbed on the particle surface, blocked in the micro interstice, located within the structure of the oxyhydroxides, or as phosphate mineral [3]. The central problem of iron ore containing phosphorus is the poor liberation of iron minerals from phosphate gangue which required fine grinding for liberation. Other problems excite regarding the liberation is high energy consumption during the very fine grinding required, and the efficiency of physical separation [4].

Many attempts of phosphorus removal to acceptable level have been made such as chemical leaching, magnetizing roasting and bioleaching. Even though some of these methods reach the target of phosphorus removal and upgrading of iron, they are still having disadvantages. They causing environmental pollution, high cost, being time-consuming and have a low level of iron recovery [4]. When the phosphorus and siliceous minerals reach a good liberation degree, it could be beneficiated by flotation or magnetic separation [2]. The flotation of Iron requires a minimal amount of reagents, low power requirement, the simplicity of facilities, availability of commercial equipment, unskilled labour and do not spoil the environment 
significantly [3]. They are three possible ways available in iron flotation; first; reverse cationic flotation of quartz, second; direct anionic flotation of iron oxides, third: reverse anionic flotation of activated silica [5]. Generally, silica is floated by an amine as a cationic collector. But "reverse" flotation using anionic collectors is also relevant by activating rock minerals (e.g., $\mathrm{Ca}^{2+}$ activation of silica) whereby depressed the iron-bearing minerals [6]. Phosphate minerals are normally floated at basic $\mathrm{pH}$ with anionic collectors, these collectors are long-chain fatty acids and their salts, especially oleic acid or its soap [7].

Reverse anionic flotation rejects quartz by first activating it with the use of lime or calcium chloride, and then floating it using fatty acids as collectors. A significant advantage of reverse anionic flotation is the skip of de-sliming prior to flotation, this type of flotation occurs at higher $\mathrm{pH}$ $(11-12)$ in which the electrostatic repulsive force between mineral particles and slime coatings is so strong at this level of $\mathrm{pH}[8]$. Filippov, Severov [9] concluded that the reverse anionic flotation has better outcomes for the flotation of fine particles than the cationic flotation. The efficiently of quartz flotation decreases at particle size coarser than $75 \mu \mathrm{m}$, for both reverse anionic and cationic flotation [10]. Sahoo, Rath [11] state that, soluble starch has been used as depression in all reverse flotation process. However, Tohry and Dehghani [12] found that sodium silicate is a better depressant for iron oxide compared to starch and dextrin, but the cations addition (such as $\mathrm{Ca}^{2+}$ ) to sodium silicate affects the selectivity of the process. Pinto, De Araujo [13] discovered that the starches are stronger depressant agents for iron oxide than for quartz and for calcite rather than apatite. They suggested the behaviour in the quartz-hematite it is due to electrostatic interactions. However, Kar, Sahoo [14] indicated the existence of hydrogen bonding and chemical interaction between hematite and starches. Yin, Han [15] investigated the flotation process of carbonaceous iron ore from Donganshan China. Two steps have been used, first; direct anionic flotation of siderite by oleic acid in $\mathrm{pH} 6-6.5$ while the hematite depressed by starch. Second; reverse anionic flotation of activated quartz using calcium oxide at $\mathrm{pH} 11.5$ with oleic acid as a collector and starch again as a hematite depression. The first step obtained a siderite concentrate containing 36.5\% Fe with $9.5 \%$ recovery, and in the next step gained $69.3 \% \mathrm{Fe}$ with $61.1 \%$ of recovery.

Microwave energy is nonionizing electromagnetic radiation which causes molecular motion by migration of ionic species and rotation of dipolar species [16]. Microwave energy has the potential for application in different mineral processing unit operations such as heating, drying, grinding, liberation, leaching, roasting, smelting, carbothermic reduction of oxide minerals, waste management, spent carbon regeneration and pre-treatment of refractory gold concentrate $[17,18]$. In liberation, ores contain minerals have hugely different mechanical and thermal properties. During radiation, the stresses of different magnitudes revealed within the lattice, both by the heating and cooling processes. This is due to significantly different thermal expansion coefficients existing between different mineralogical species the stresses lead to localized fractures of an intergranular and trans-granular nature but not necessarily to catastrophic failure. Hence, the clean liberation of the valuable minerals would be possible and that leads to an improvement in concentration grade and metal recovery after beneficiation [19]. The microwave also proved its ability to increase magnetic susceptibility for weakly paramagnetic ores and minerals [20]. Haque [17] reported that microwave heating and a flotation mixture also improve flotation performance. Hightemperatures were not necessary for microwave pre-treatment as the differential expansion properties of each mineral phases were controlling strength reduction mechanism. Therefore, remarkable increases in grindability were possible for materials exposed to microwave radiation for short ( $<10$ seconds) exposure times [21].

Guo [22] established the influence of microwave heating on the grinding of Panzhihua ilmenite ore in China. Microwave radiation time, power density and particle size were factors of influence. The effectiveness of these factors studied by SEM and magnetic separation which indicated intergranular fractures and liberation of 
minerals respectively. $40 \mathrm{~g}$ sample was microwave heated for $30 \mathrm{sec}$ with $1000 \mathrm{~W}$ of microwave power and followed by water quenching, increased the recovery of magnetic separation from $44 \%$ for raw ore to $72 \%$ by microwave treatment. Kumar, Sahoo [23] improved the grindability of iron ore by microwave pre-treatment. They suggested that may due to the thermal stress cracking in boundaries showed by SEM analysis. Omran [4] studied the use of microwave treatment in combination with physical separation and found that microwave heating increase liberation, improves magnetic properties and reduces the time of iron ore processing. He conducted $59 \%$ of dephosphorization. Even though the process of iron occurred by microwave and magnetic, it couldn't get to an acceptable level of phosphorus due to the large particle size required in magnetic separation.

The current work presents firstly, a novel microwave heating as a pre-treatment this can assist in grinding and liberation between iron minerals and gangues (silica, clay and apatite) by creating microcracks due to the different thermal expansion. Secondly, applying reverse anionic flotation to get an advantage to the fact that activated silica and apatite (main gangue) are both floating by fatty acid.

\section{MATERIAL AND METHODS}

\section{A. Materials}

The iron ore samples have been taken from Bajrawia at the Nile State, Sudan. Trenches -which the samples have been collected frommade by Bajrawia Mining Company located 16057'14.2' N, 33॰48'15.7' E. Trenches areas are about $(7.4 \times 2.4) \mathrm{m}^{2}$ and $428 \mathrm{~m}$ over the sea, in each side of the trench the samples have been collected and recorded their information. Samples were crushed by laboratory jaw and roll crushers then screened. The product was mixed with coning and quartering method. The chemical composition of the iron ore sample was determined by AAS and X-ray fluorescence spectrometer (XRF) model Axios, Netherlands. Microstructures inspection of the samples were done by optical microscope OLYMPUS BX51, Nikon Eclipse E100 microscope with a digital camera, Scanning Electron Microscope TECSAN and SEM/EDS VEGA3 with an OXFORD X-ray detector. The mineralogical analysis was carried out using X-ray diffraction analysis (XRD) model Empyrean-panalytical.

In reverse anionic flotation experiments, the following reagents were used: Starch soluble (potato), Calcium chloride $\left(\mathrm{CaCl}_{2}\right)$, Oleic acid $\left(\mathrm{C}_{18} \mathrm{H}_{34} \mathrm{O}_{2}\right)$, Sodium hydroxide and Sulphuric acid were provided by (S D Fine-Chem Limited company, India). Methyl-isobutyl-carbinol (MIBC) $\left(\mathrm{C}_{6} \mathrm{H}_{14} \mathrm{O}\right)$ was supplied by (Laboratory Reagents and Fine Chemicals company, India). Small test laboratory flotation machine model XFD II used in the flotation experiments. The cell boundary dimension is $520 \times 338 \times 770 \mathrm{~mm}^{3}$, impeller diameter $45 \mathrm{~mm}$ with the rotary speed of 2800 $\mathrm{RPM}$, total weight is $30 \mathrm{Kg}$ and groove capacity of 0.5 litres. A microwave oven (LG, model MS-1944W/00 and cavity dimension 315×203 ×294 $\mathrm{mm}^{3}$ ) with a maximum output power of $700 \mathrm{~W}$ was used in the treated iron ore samples at varying power levels and exposure times. Digital thermometer model (TP101) has $1 \mathrm{C}^{\circ}$ of accuracy and can measure temperature from -50 Co to +300 Co.

\section{B. Methods}

\section{* Reverse anionic Flotation}

Table 1 shows the steps of flotation experiments in which five parameters were considered including particle size, $\mathrm{pH}$, depressant dosage, activator dosage and collector dosage. The flotation time was set $5.5 \mathrm{~min}$ for all experiments and there was $2 \mathrm{~min}$ between the addition of the reagents for conditioning. The reagents were added in three or four stages and the pulp density is $45 \%$. The optimization of factors happened by changing one factor and fix the rest, then moved to the next factor, one by one. The optimum variable for each factor was chosen based on iron grade, iron recovery of concentrate and phosphorus contained in concentrate. All experiments have analysed using XRF. 
Table 1. Experiments of reverse anionic flotation

\begin{tabular}{cccccc}
\hline \multirow{5}{*}{ Factor } & $\begin{array}{c}\text { Particle } \\
\text { size, } \\
\text { D80 } \\
(\mu \mathrm{m})\end{array}$ & $\mathrm{pH}$ & $\begin{array}{c}\text { Depressant } \\
\left(\mathrm{g} / \mathrm{m}^{3}\right)\end{array}$ & $\begin{array}{c}\text { Activator } \\
\left(\mathrm{kmol} / \mathrm{m}^{3}\right)\end{array}$ & $\begin{array}{c}\text { Collector } \\
\left(\mathrm{kmol} / \mathrm{m}^{3}\right)\end{array}$ \\
\hline \multirow{5}{*}{ Variables } & 32 & 1 & 160 & $1 \times 10^{-4}$ & $1 \times 10^{-4}$ \\
& 105 & 7 & 980 & $5 \times 10^{-4}$ & $5 \times 10^{-4}$ \\
& 150 & 9 & 1600 & $1 \times 10^{-3}$ & $1 \times 10^{-3}$ \\
& -3 & 5 & 640 & $5 \times 10^{-3}$ & $5 \times 10^{-3}$ \\
& -- & 11 & --- & --- & $1 \times 10^{-2}$ \\
& --- & 13 & --- & -- & -- \\
\hline
\end{tabular}

\section{Microwave Pre-treatment}

$100 \mathrm{~g}$ of representative samples were placed in the microwave oven in the crucible. The temperature of the test samples was measured by quickly inserting a digital thermometer into the middle of the sample after the power was turned off Fig. 1. The measured temperatures are the bulk temperatures of the samples, which allowed to cool in the microwave oven to room temperature.

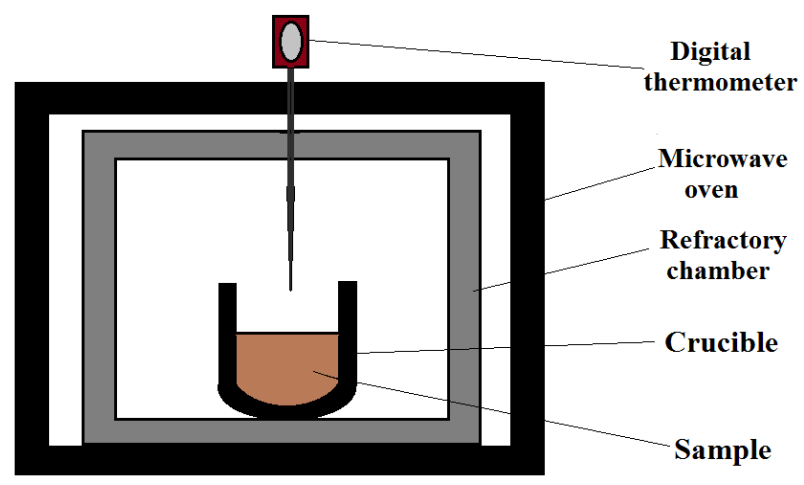

Fig. 1. Schematic diagram of the microwave experimental equipment

Table 2 shows the experiments of microwave pre-treatment on flotation, whereas three microwave parameters including particle size, power density and radiation time optimized according to their effect on reverse anionic flotation which represents on iron grade, iron recovery of concentrate and phosphorus contained in concentrate.
Table 2. Microwave experiments

\begin{tabular}{|c|c|c|c|}
\hline Factor & $\begin{array}{c}\text { Radiation } \\
\text { time } \\
(\mathrm{sec})\end{array}$ & $\begin{array}{l}\text { Power } \\
\text { density } \\
\text { (W) }\end{array}$ & $\begin{array}{c}\text { Range of Particle } \\
\text { size } \\
(\mathrm{mm})\end{array}$ \\
\hline \multirow{4}{*}{ Variables } & 40 & 420 & +6.3 \\
\hline & 80 & 560 & $-6.3+4.75$ \\
\hline & 120 & 700 & $-4.75+2$ \\
\hline & --- & --- & -2 \\
\hline
\end{tabular}

\section{RESULTS AND DISCUSSION}

\section{A. Chemical Characterization}

The chemical analysis of Bajrawia iron ore representative sample using XRF is shown in Table 3. The sample contains $35.7 \%$ of Fe, which is a very low grade in nature. The major impurities are $\mathrm{SiO}_{2}(30.5 \%), \mathrm{Al}_{2} \mathrm{O}_{3}(11.8 \%)$ and $\mathrm{P}_{2} \mathrm{O}_{5}(0.849 \%)$. The AAS and titration analysis was confirmed that the sample contains $35.12 \%$ and $36.12 \%$ respectively. The result of SEM-EDX in Fig. 3 showed that the sample also contained $35.33 \% \mathrm{Fe}, 0.32 \% \mathrm{P}, \mathrm{Si}$ and $\mathrm{Al}$. Moreover, the main minerals are goethite, clay minerals and quartz.

Table 3. Average Chemical analysis of Bajrawia iron ore sample

\begin{tabular}{cc}
\hline Element & Assay \% \\
\hline $\mathrm{Fe}_{2} \mathrm{O}_{3}$ & 51.034 \\
$\mathrm{Fe}$ & 35.72 \\
$\mathrm{SiO}_{2}$ & 30.456 \\
$\mathrm{Al}_{2} \mathrm{O}_{3}$ & 11.810 \\
$\mathrm{CaO}$ & 1.297 \\
$\mathrm{P}_{2} \mathrm{O}_{5}$ & 0.849 \\
$\mathrm{P}$ & 0.370 \\
$\mathrm{SO}_{3}$ & 0.240 \\
$\mathrm{TiO}_{2}$ & 0.538 \\
$\mathrm{Mn}_{3} \mathrm{O}_{4}$ & 0.554 \\
$\mathrm{Others}$ & 3.439 \\
\hline
\end{tabular}

According to those results of chemical analysis, it is clear that the Bajrawia iron ore contains about $35.5 \%$ Fe and require beneficiation by removing the impurities such as silica and 
phosphorus to meet the international specifications of the steel industry.

\section{B. Mineralogical Characterization}

From the XRD result Fig. 2, goethite and hematite occur as iron-bearing mineral, but goethite is more than hematite (3:1). Kaolinite is the aluminum bearing silicate gangue phase and quartz is the silica mineral. From optical microscope and SEM studies, it is observed that iron oxide filling -pore- the spaces between rounded to sub-rounded quartz grains (i.e. not subjected to transportation from its source) and brown clayey fragments which indicate that iron oxide is the sedimentary origin. The iron ore mainly contains goethite and few of hematite, traces of apatite, kaolinite (clay) also was observed. Iron ore sample is disseminated and contains a small grains size of silica with an average size of $45 \mu \mathrm{m}$. These characteristic reveals that this iron ore is difficult to process one.
C. Reverse Anionic Flotation

- Effect of Particle size

The effect of particle size on iron grade, recovery and phosphorus content is shown in Fig. 3 and 4. It is seen that the recovery of iron concentrate increases as particle size increases, however, it decreases with iron grade. The reason of that is the liberation of iron particle have a full effect of the depressant. Moreover, the efficiently of silica flotation decreases at particle size coarser then $75 \mu \mathrm{m}$ [10]. Phosphorus has a different direction of iron which should be with the froth, particle size less than $63 \mu \mathrm{m}$ obtained a minimum amount of phosphorus and higher content of iron, this due to the liberation of phosphorus from the iron particle and adsorption of the collector. The most effective particle size is $\mathrm{D}_{80}=63 \mu \mathrm{m}$.

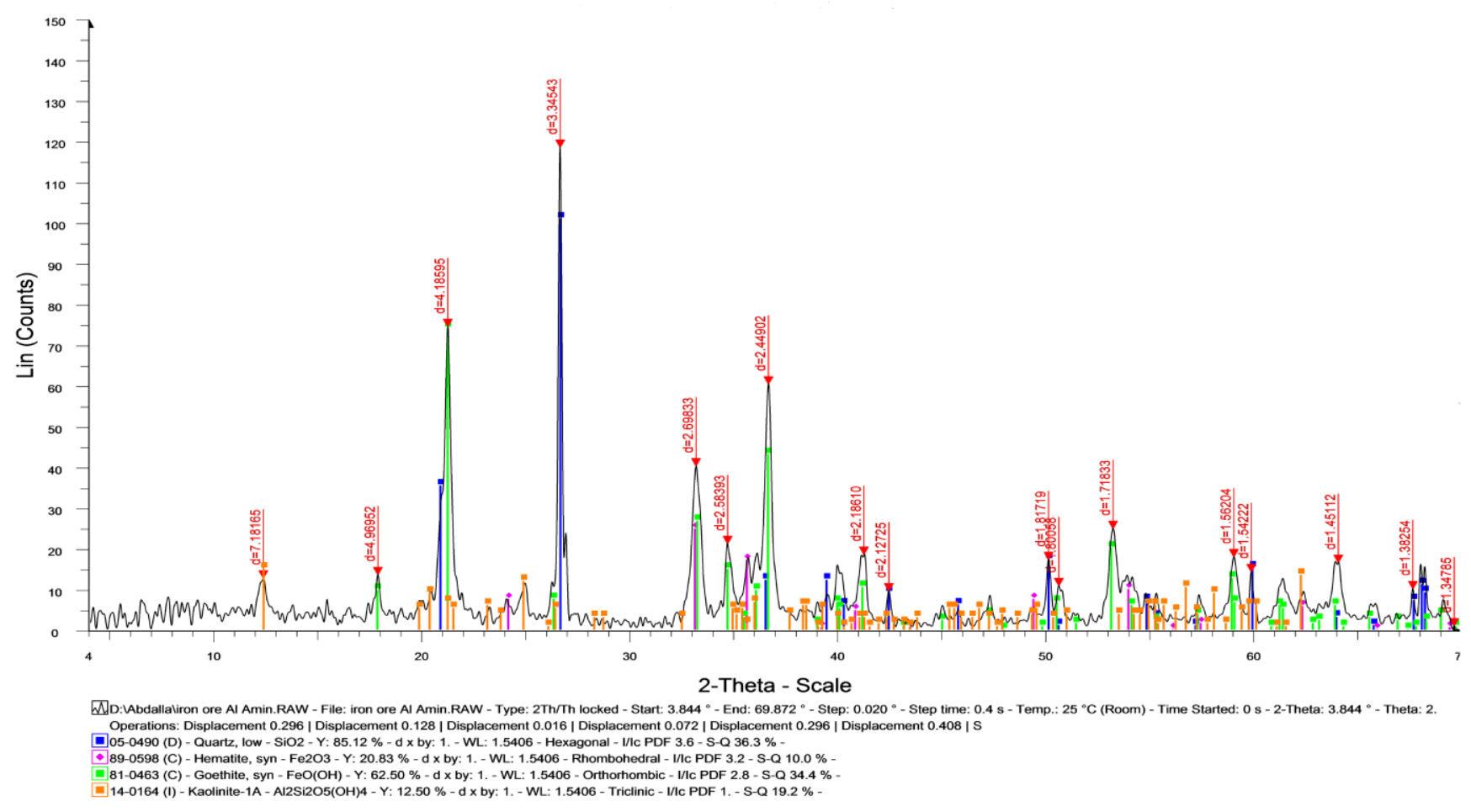

Fig. 2. XRD pattern of the iron sample 


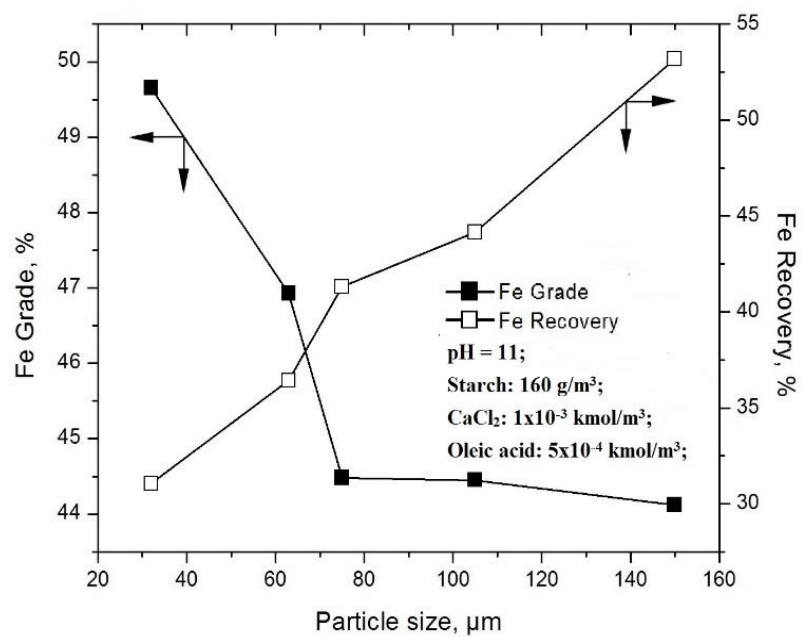

Fig. 3. Effect of particle size on iron grade and recovery of iron concentrate

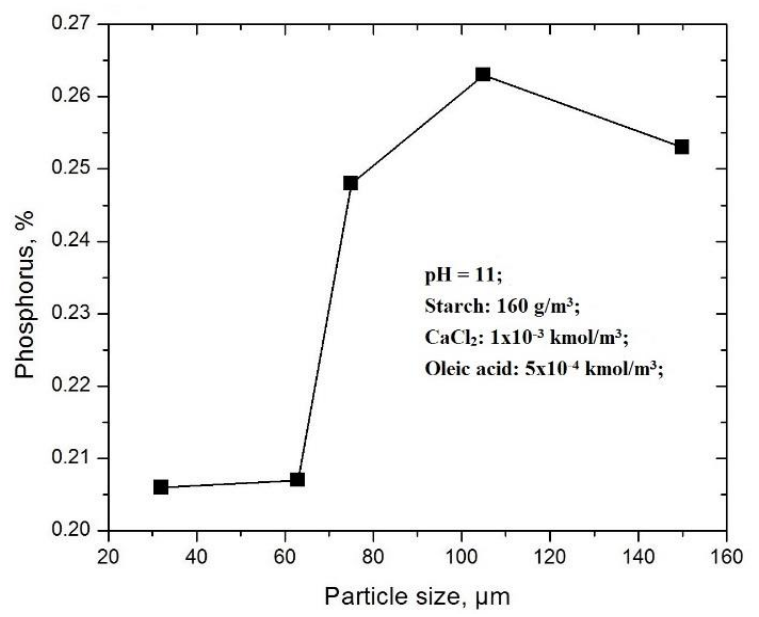

Fig. 4. Effect of particle size on phosphorus

\section{Effect of $\mathrm{pH}$ of the pulp}

The variations of iron grade and recovery of concentrate with the change of $\mathrm{pH}$ of the pulp are shown in Fig. 5 and 6. It was observed that the silica particles and phosphorus did not float at any point of acidic media, but after natural $\mathrm{pH}$ they were slowly floating as $\mathrm{pH}$ increased reaching its maximum at $\mathrm{pH} 11$ and dropped again. The reason for that is a weakly acidic fatty acid like oleic acid undergo dissociation to form ions (RCOO-) at high $\mathrm{pH}$ values and neutral molecules $(\mathrm{RCOOH})$ at low $\mathrm{pH}$ values. In average $\mathrm{pH}$ region, the ions and neutral molecules can companion to form ionic-molecular $(\mathrm{RCOOH}$, RCOO-) complexes as in fig. 7 [24]. The drop of grade happened because of the addition of more negative hydroxyl ions which affected positive calcium ions [25]. There was a small natural selectivity of oleate towards phosphate minerals above $\mathrm{pH} 9.5$ [26]. Moreover, starch is not absorbed on the surface of quartz at the alkaline $\mathrm{pH}$ of the pulp [12].

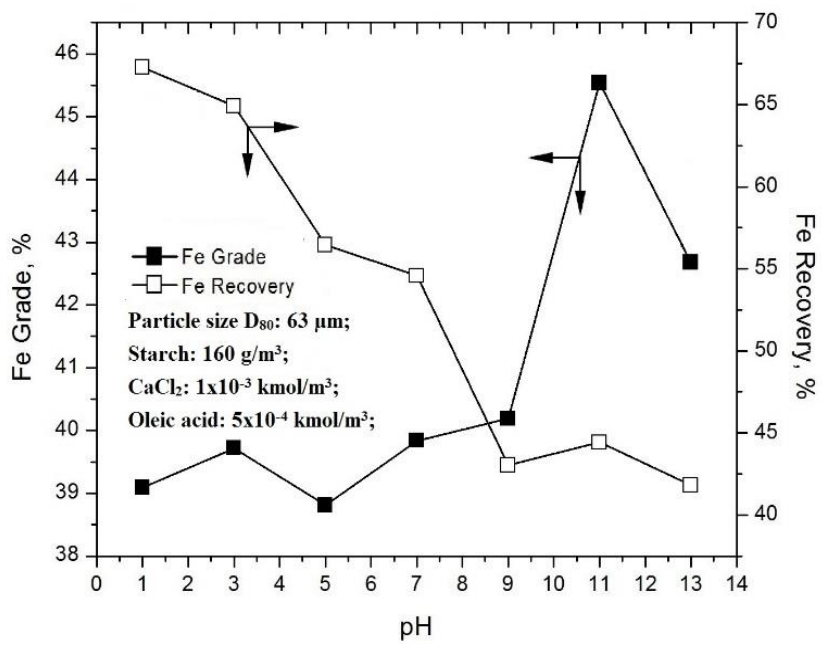

Fig. 5. Influence of $\mathrm{pH}$ as a function of iron grade and recovery of iron concentrate

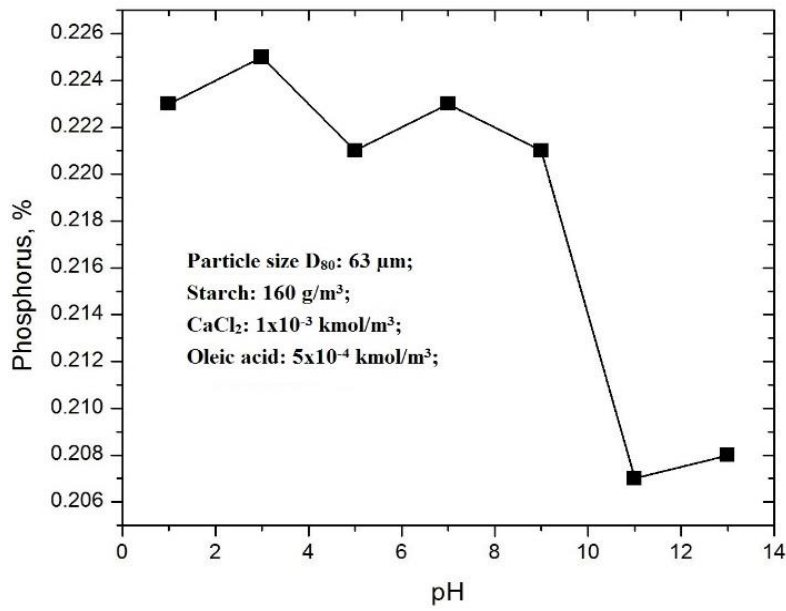

Fig. 6. Influence of $\mathrm{pH}$ as a function of phosphorus

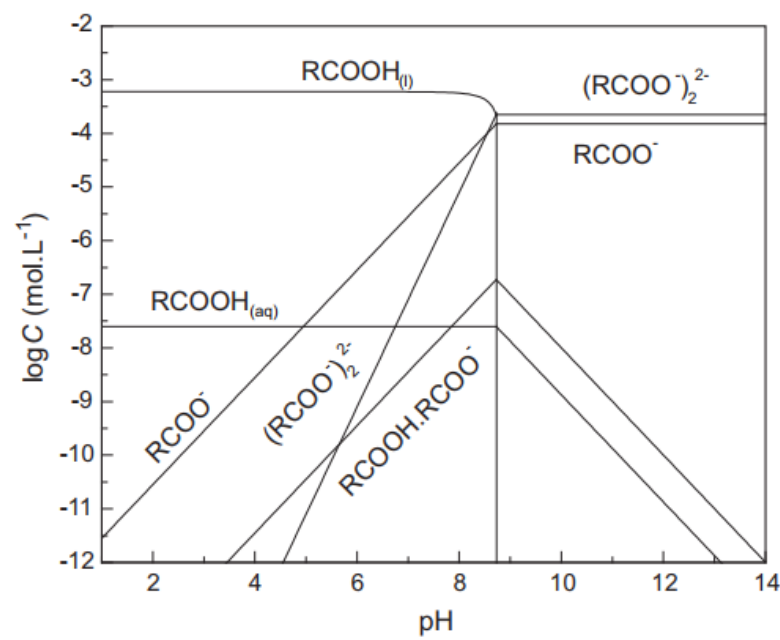

Fig. 7. Species distribution diagram of oleic acid

\section{Effect of Starch dosage}

Soluble potato starch was used as a depressant of iron oxide. From Fig. 8 and 9, it can be seen that increases in starch dosage the iron grade, iron recovery of concentration and 
dephosphorization increase as well, but further addition of starch dosage over $960 \mathrm{~g} / \mathrm{m}^{3}$ have a negative effect on iron recovery of concentration and dephosphorization. The reason for that is the more addition of starch means more iron oxides depressed. However, with the extra addition of depressant, starch effects on phosphorus flotation.

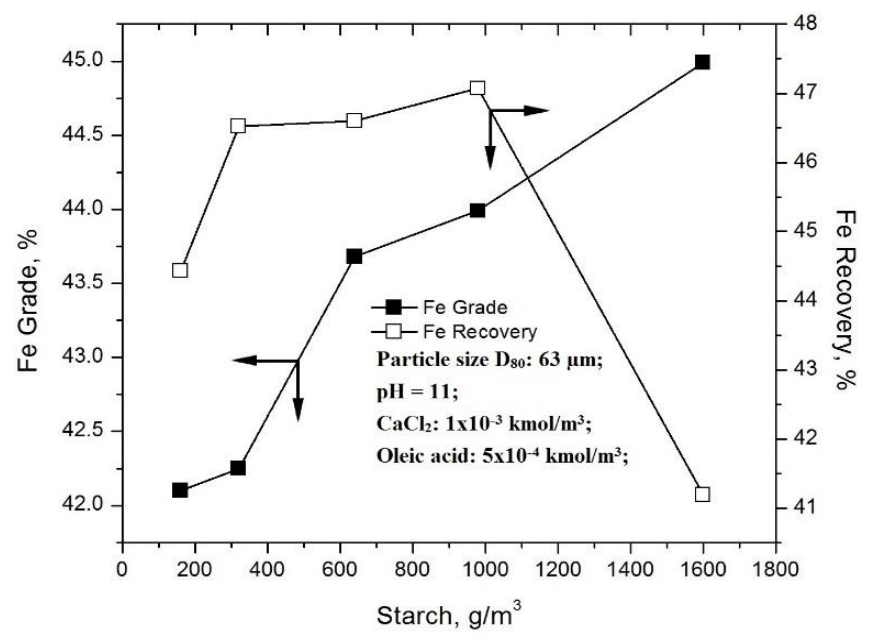

Fig. 8. Effect of starch dosage on iron grade and recovery of iron concentrate

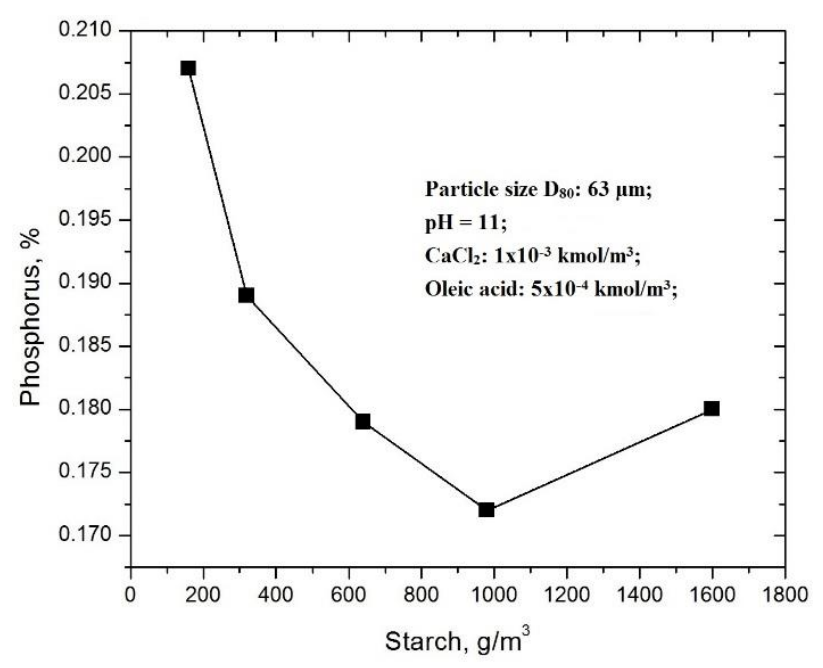

Fig. 9. Effect of starch dosage on phosphorus

\section{* Effect of Calcium Chloride dosage}

The effect of calcium chloride on iron grade, iron recovery and phosphorus were examined at Fig. 10 and 11, it was found that calcium chloride effectively activated the silica at dosage $5 \times 10^{-4}$ $\mathrm{kmol} / \mathrm{m}^{3}$ which reflects at iron grade and its recovery. More addition of calcium ions, the flotation lost its selectivity [27]. The adsorption of starch on iron oxides was shown to be strongly dependent on the presence of calcium ion, but it is not well understood [12].

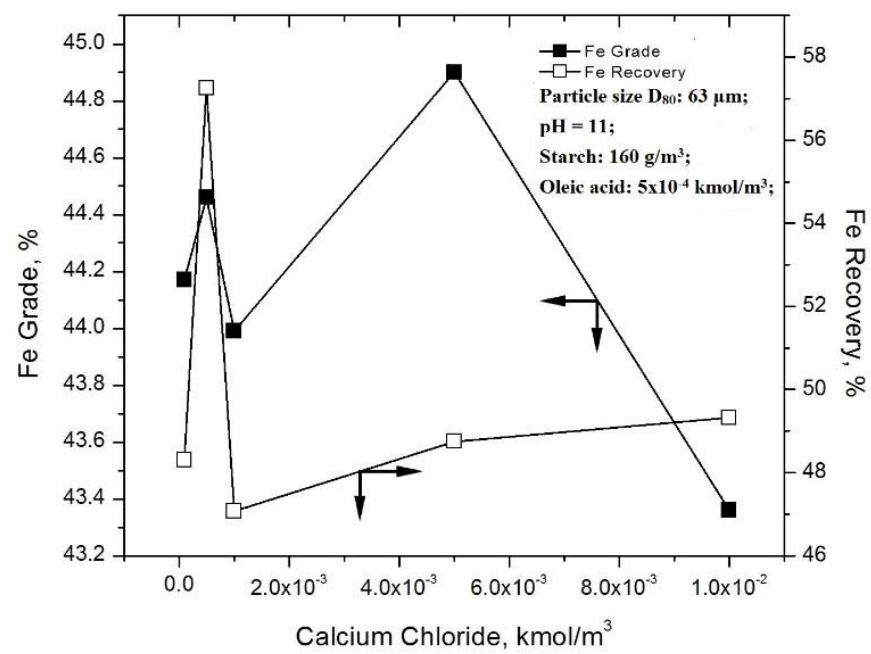

Fig. 10. Effect of calcium chloride dosage on iron grade and recovery of iron concentrate

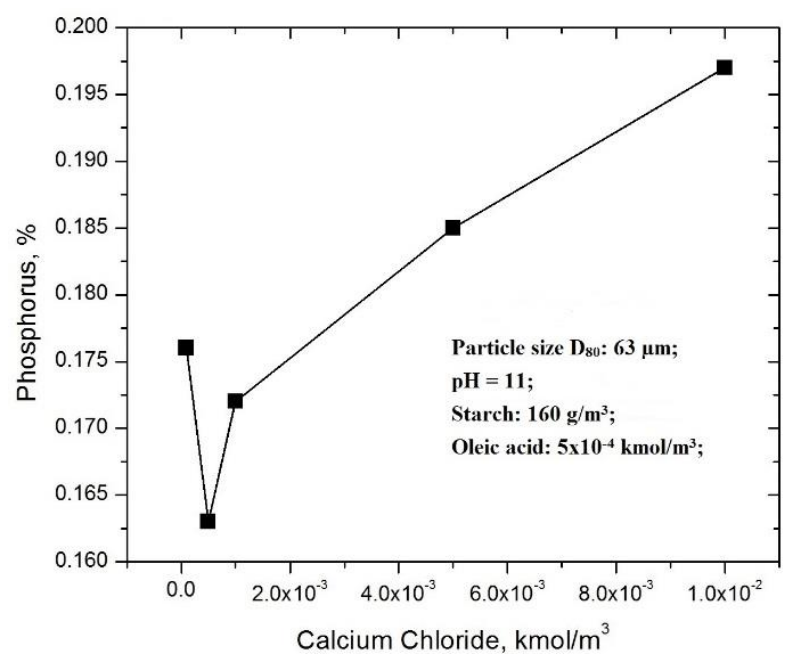

Fig. 11. Effect of calcium chloride dosage on phosphorus

\section{Effect of Oleic acid dosage}

Fig. 12 and 13 demonstrated that the iron recovery of concentration increases with an increase in oleic acid dosage. On the other hand, iron grade and phosphorus have -almost- no effect at the first oleic acid dosages, but with more addition of oleic, they show improvement in iron grade and dephosphorization. Thus, due to an increase in the negativity of oleic acid as in Fig. 7. In the beginning, the collector dosages were not enough to cover the silica and phosphorus surfaces which indicated to increase the dosage of the collector until dropping the flotation performance. Hence, the maximum amount of collector is the best. 


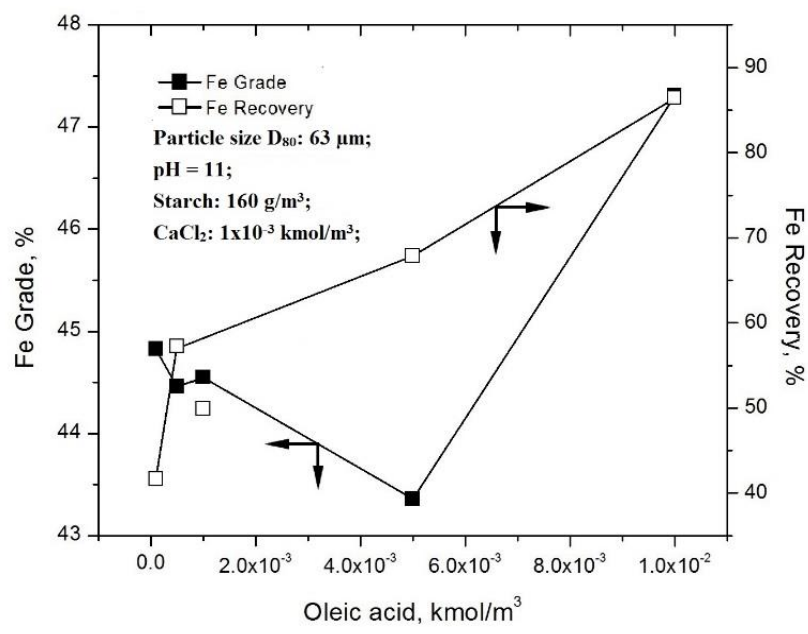

Fig. 12. Effect of oleic acid dosage on iron grade and recovery of iron concentrate

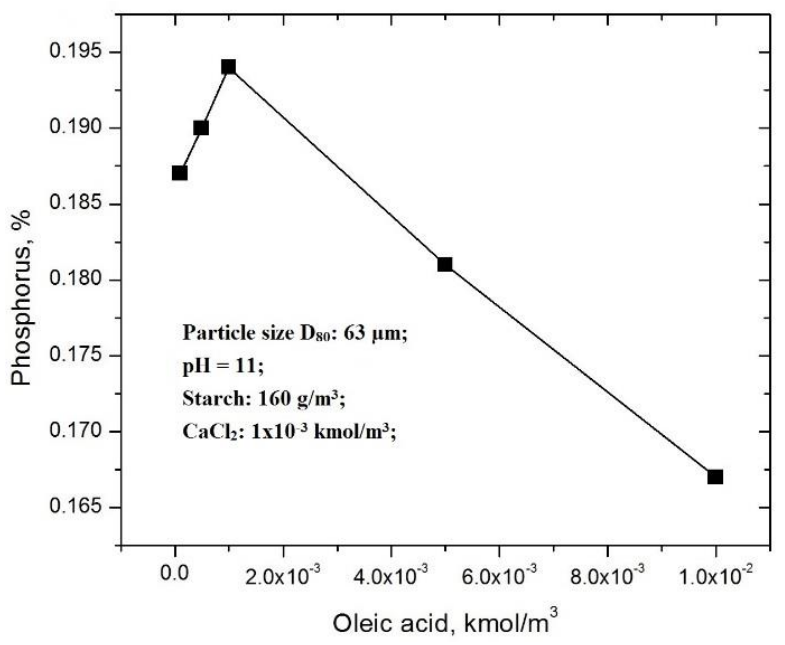

Fig. 13. Effect of oleic acid dosage on phosphorus

The optimum variables of reverse anioni flotation are; particle size $\mathrm{D}_{80}: 63 \mu \mathrm{m}, \mathrm{pH}=11$. starch: $980 \mathrm{~g} / \mathrm{m}^{3}$, calcium chloride: $5 \times 10^{-4} \mathrm{kmol} / \mathrm{m}^{3}$ and oleic acid: $1 \times 10^{-2} \mathrm{kmol} / \mathrm{m}^{3}$ which obtained $47.31 \% \mathrm{Fe}, 86.43 \%$ recovery of iron and $0.167 \%$ of phosphorus.

\section{Microwave pre-treatment on the reverse anionic flotation}

\section{* Effect of Radiation time}

The effect of radiation time on flotation efficiency is shown in Fig. 14 and 15 it was found that the increase in time improved the efficiency of reverse flotation and also rose the temperature. The main reason for that is during microwave heating goethite and hematite is a dielectric (absorbers) material, while gangue minerals are either have fewer dielectric properties (apatite) or insulators which does not heat (quartz). Hence, the iron minerals expanded more than gangue which resulting intergranular fractures and increases the liberation. It was also found that raises the temperature enhances the expansion.

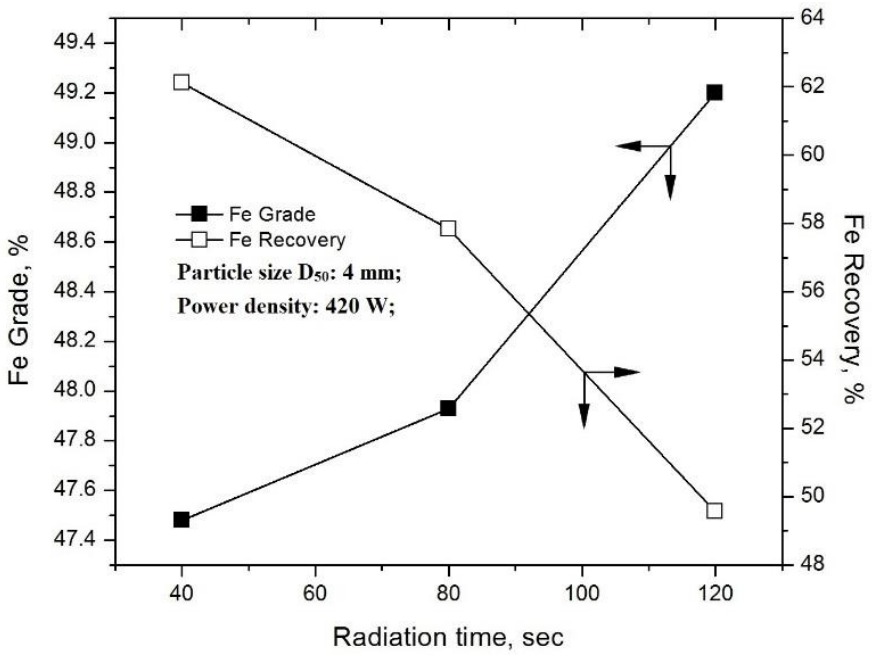

Fig. 14. Effect of radiation time on iron grade and recovery of iron concentrate

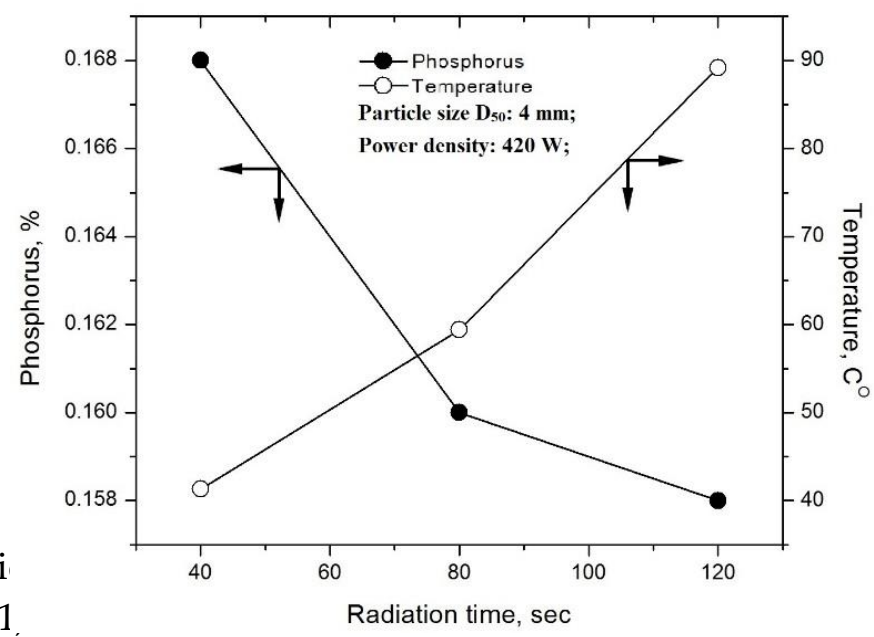

Fig. 15. Effect of radiation time on phosphorus and temperature

\section{Effect of Power density}

Fig. 16 and 17 show the effect of power density on the performance of reverse flotation operation. It was observed that increases in power density lead to rises in heat temperature which result in more expansion of active materials. The proportion between radiation time and power density with flotation performance (liberation) is not ultimate, at some point beyond the particle of the sample will start melting [28]. 


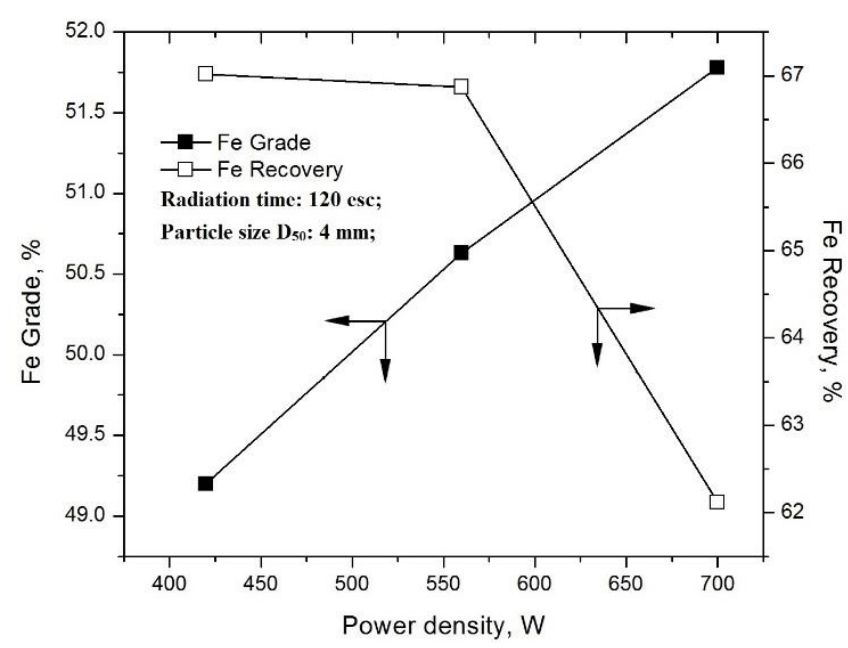

Fig. 16. Effect of power density on iron grade and recovery of iron concentrate

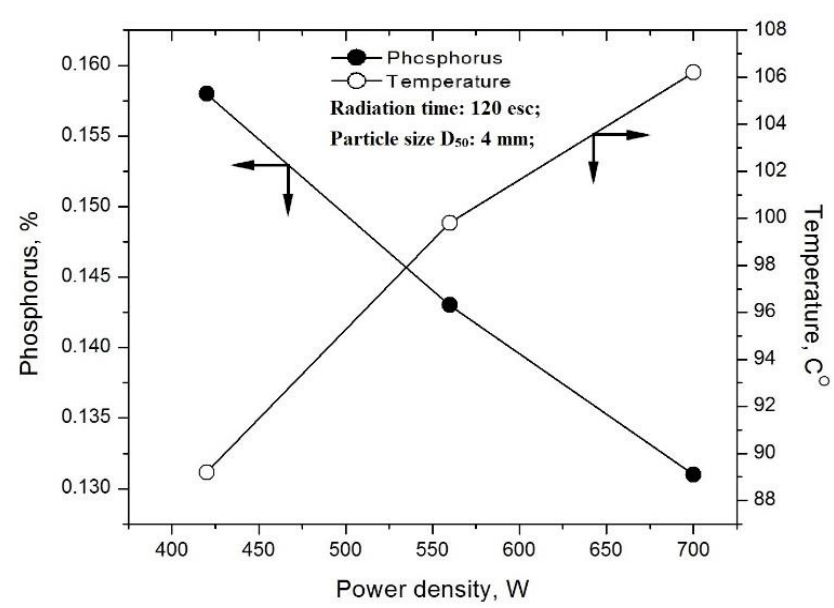

Fig. 17. Effect of power density on phosphorus and temperature

\section{Effect of Particle size}

Fig. 18 and 19 illustrate the effect of particle size on heating rate and flotation operation. The sample temperature rises as particle size become coarser resulting in easily liberate the minerals and getting better performance on flotation. This result indicates that microwave treatment in more effective at coarse size fractions compared to finer fractions. Therefore, the stress generated on coarse grain size is more significant than on finer grain size. This result perhaps explained by the fact that larger particles will retain heat longer than a small particle [21].

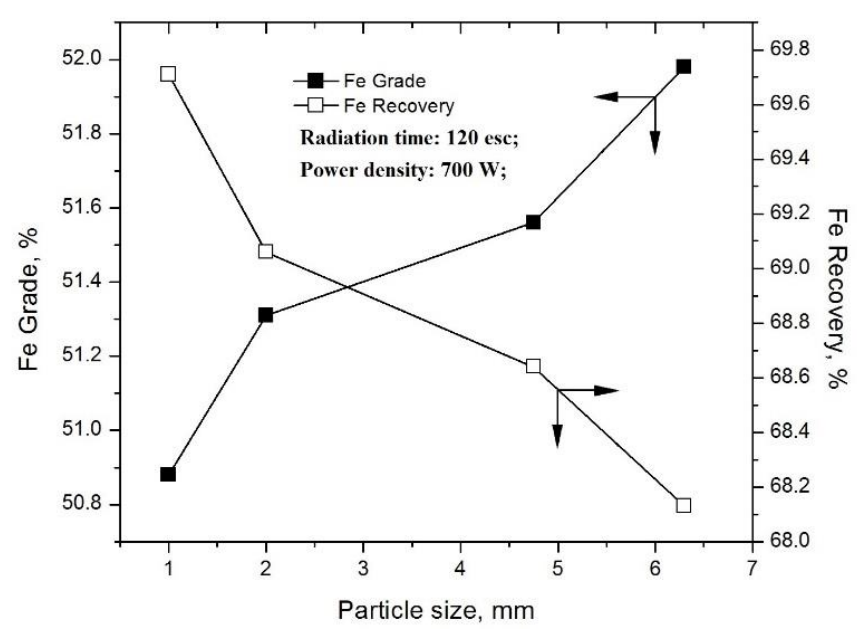

Fig. 18. Effect of particle size on iron grade and recovery of iron concentrate

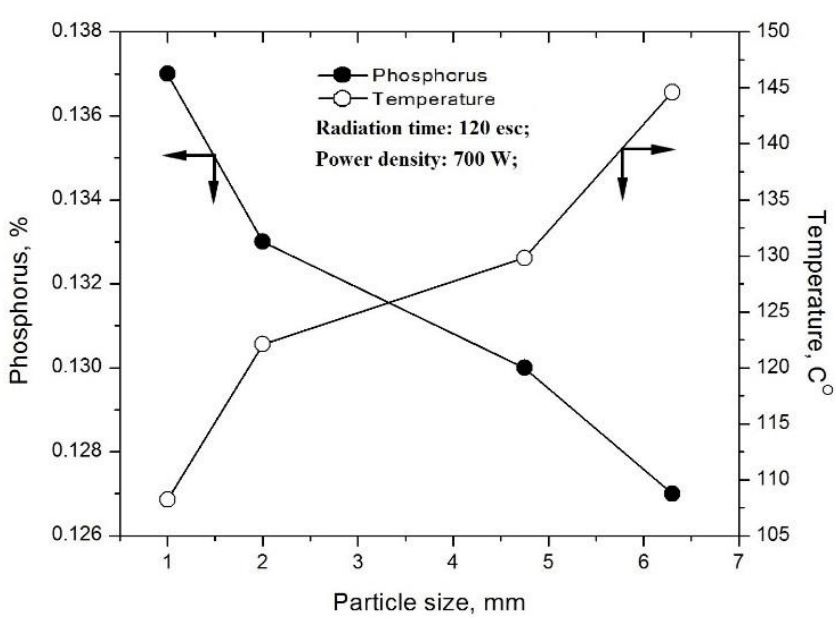

Fig. 19. Effect of particle size on phosphorus and temperature

Images took by SEM before and after of microwave treatment, the microcracks are difficult to observe due to the complex structure of the iron ore Fig. 20. The black spots in the images confirm that the ore has a high degree of porosity.

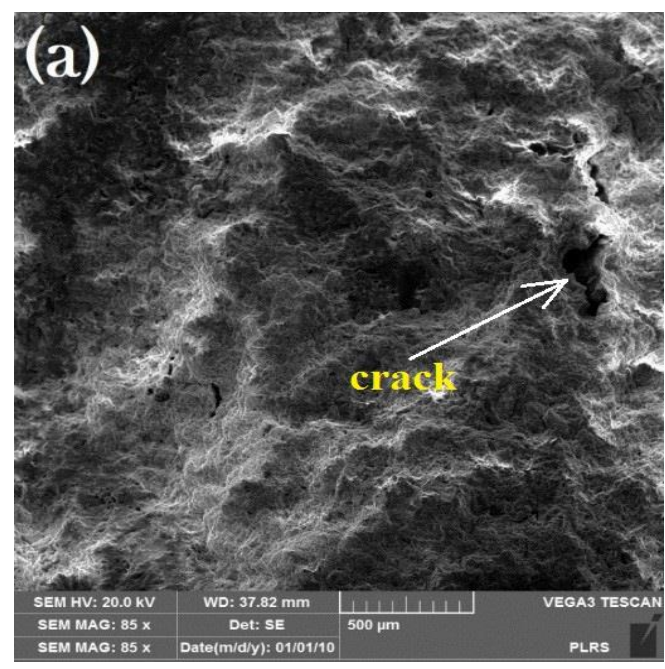




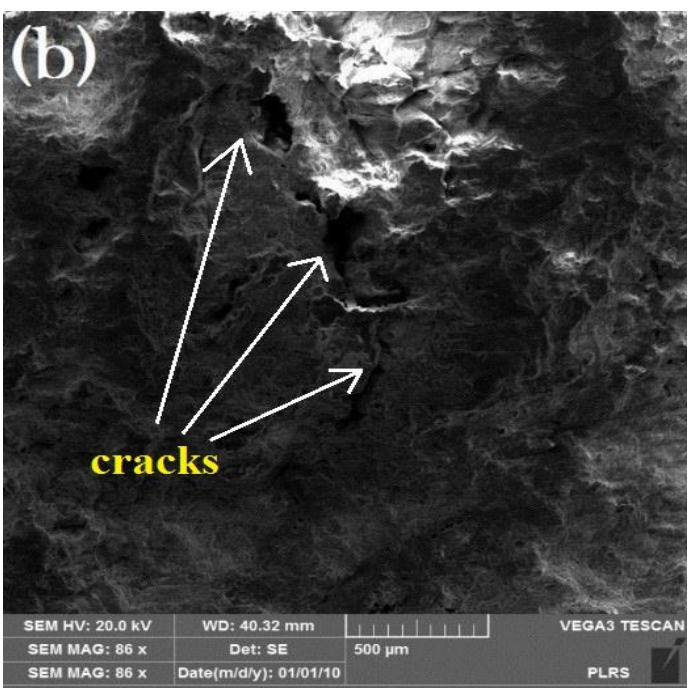

Fig. 20. SEM image of iron ore

a) Before microwave treatment b) After microwave treatment

From microwave pre-treatment results, it is possible to improve iron grade to $51.98 \%$ Fe with the recovery of $68.15 \%$, while phosphorus also decreases to $0.127 \%$.

\section{CONCLUSION}

The fundamental issue associated with exploiting high phosphorus iron ore is the very fine dissemination. These very fine phosphate particles are very difficult to separate from conventional mineral processing techniques. The present study applied a novel method to improve flotation performance as well as removal of phosphorus from low-grade and high -phosphorus iron ore through the utilization of microwave pre-treatment prior to reverse anionic flotation.

Mineralogical and chemical characterization of the sample showed that goethite is the main iron oxide with less hematite and contains $35.71 \%$ of iron, $30.5 \%$ of silica and $0.37 \%$ of phosphorus. The reverse anionic flotation experiments were conducted to obtain the best conditions in an account of iron upgrading and phosphorus removal. Optimized parameters of RAF - particle size of $63 \mu \mathrm{m}, \mathrm{pH}$ of $11,980 \mathrm{~g} / \mathrm{m}^{3}$ of Starch (depressant), $5 \times 10^{-4} \mathrm{kmol} / \mathrm{m}^{3}$ of calcium chloride (activator) and $1 \times 10^{-2} \mathrm{kmol} / \mathrm{m}^{3}$ of oleic acid (collector) - obtained $47.31 \% \mathrm{Fe}, 86.43 \%$ recovery of iron and $0.167 \%$ of phosphorus.

The influence of microwave radiation time, power density and particle size on the liberation of iron ore showed a respectable improvement of the performance of RAF; $51.98 \% \mathrm{Fe}, 68.15 \%$ recovery and $0.127 \%$ phosphorus were obtained at $700 \mathrm{~W}$ of power density, $120 \mathrm{sec}$ of radiation time and $+6.3 \mathrm{~mm}$ particle size. The optimization of microwave heating indicated that microwave heating is more effective at coarser grain size, higher microwave power intensity and longer radiation time.

\section{Acknowledgments}

The authors wish to thank Eng. M. Moutasim and GRAS laboratory for preparation and analysis of samples. The author's gratitude is extended to Dr O. Satti and Prof. M. Talballa for their help at various stages of this work.

\section{REFERENCES}

1. Ahmed, A.A.M., et al., Bajrawia Iron Ore Deposits Geology, Grade and Reserve Estimation. 2010.

2. Nunes, A.P.L., et al., Floatability studies of wavellite and preliminary results on phosphorus removal from a Brazilian iron ore by froth flotation. Minerals Engineering, 2012. 39: p. 206-212.

3. Pereira, A.C. and R.M. Papini, Processes for phosphorus removal from iron ore-a review. Rem: Revista Escola de Minas, 2015. 68(3): p. 331-335.

4. Omran, M., Microwave Dephosphorization of High Phosphorus Iron Ores of The Aswan Region, Egypt, in Process and Environmental Engineering 2015, University of Oulu: Finland

5. Araujo, A., P. Viana, and A. Peres, Reagents in iron ores flotation. Minerals Engineering, 2005. 18(2): p. 219-224.

6. Vidyadhar, A. and R. Singh, Froth Flotation and its Application to Concentration of Low Grade Iron Ores. 2007.

7. Sis, H. and S. Chander, Reagents used in the flotation of phosphate ores: a critical review. Minerals Engineering, 2003 16(7): p. 577-585

8. Ma, M., Froth flotation of iron ores. International Journal of Mining Engineering and Mineral Processing, 2012. 1(2): p. 56-61.

9. Filippov, L., V. Severov, and I. Filippova, An overview of the beneficiation of iron ores via reverse cationic flotation. International journal of mineral processing, 2014. 127: p. 62-69.

10. Ma, X., M. Marques, and C. Gontijo, Comparative studies of reverse cationic/anionic flotation of Vale iron ore International Journal of Mineral Processing, 2011. 100(3-4): p. 179-183.

11. Sahoo, H., et al., Role of silica and alumina content in the flotation of iron ores. International Journal of Mineral Processing, 2016. 148: p. 83-91.

12. Tohry, A. and A. Dehghani, Effect of sodium silicate on the reverse anionic flotation of a siliceous-phosphorus iron ore Separation and Purification Technology, 2016. 164: p. 28-33.

13. Pinto, C., A. De Araujo, and A. Peres, The effect of starch amylose and amylopectin on the depression of oxi-minerals. Minerals Engineering, 1992. 5(3-5): p. 469-478. 
14. Kar, B., et al., Investigations on different starches as depressants for iron ore flotation. Minerals Engineering, 2013. 49: p. 1-6.

15. Yin, W.-Z., Y.-x. Han, and F. Xie, Two-step flotation recovery of iron concentrate from Donganshan carbonaceous iron ore. Journal of Central South University of Technology, 2010. 17(4): p. 750-754.

16. Guo, S.-h., et al., Microwave assisted grinding of ilmenite ore. Transactions of Nonferrous Metals Society of China, 2011. 21(9): p. 2122-2126.

17. Haque, K.E., Microwave energy for mineral treatment processes - a brief review. International Journal of Mineral Processing, 1999. 57(1): p. 1-24.

18. Kingman, S., Recent developments in microwave processing of minerals. International materials reviews, 2006. 51(1): p. $1-12$.

19. Kingman, S. and N. Rowson, Microwave treatment of minerals-a review. Minerals Engineering, 1998. 11(11): p. 1081-1087.

20. Lovás, M., et al., The application of microwave energy in mineral processing-a review. Acta Montanistica Slovaca, 2011. 16(2): p. 137.

21. Kingman, S., W. Vorster, and N. Rowson, The influence of mineralogy on microwave assisted grinding. Minerals engineering, 2000. 13(3): p. 313-327.

22. Guo, S.-H., et al., Microwave assisted grinding of ilmenite ore. Transactions of Nonferrous Metals Society of China, 2011. 21(9): p. 2122-2126.

23. Kumar, P., et al., Iron ore grindability improvement by microwave pre-treatment. Journal of industrial and engineering chemistry, 2010. 16(5): p. 805-812.

24. $\mathrm{Yu}, \mathrm{F}$., et al., Role of oleic acid ionic-molecular complexes in the flotation of spodumene. Minerals Engineering, 2014. 71: p 7-12.
25. El-Salmawy, M., Y. Nakahiro, and T. Wakamatsu, The role of alkaline earth cations in flotation separation of quartz from feldspar. Minerals Engineering, 1993. 6(12): p. 1231-1243.

26. Qi, G.W., et al., Selective flotation of apatite from iron oxides. International journal of mineral processing, 1992. 34(1-2): p. 83-102.

27. Qun, W. and K. Heiskanen, Batch flotation tests by fatty acid on a phosphate-iron oxide-silicate regolith ore sample from Sokli, Finland. Minerals engineering, 1990. 3(5): p. 473-481.

28. Omran, M., et al., Microwave Assisted Liberation of High Phosphorus Oolitic Iron Ore. Journal of Minerals and Materials Characterization and Engineering, 2014. 02(05): p. 414-427.

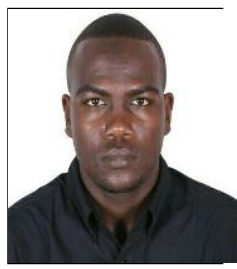

Ahmed Mohammedelmubarak Ahmed Abbaker was born in Omdurman, Sudan on September $30^{\text {th }}$, 1993. He earned a B.Sc. in Mining Engineering in 2015 from Omdurman Islamic University, Omdurman, Sudan. In late 2018, he got a M.Sc. in Mineral processing form the same university.

He worked as a teaching assistant in Mining department at the faculty of Engineering Sciences of Omdurman Islamic University since 2015 up to date 